\title{
Evaluation of the dual source model to simulate transpiration and evaporation of tomato plants cultivated in a solar
} greenhouse

\author{
X.W. Gong ${ }^{1}$, J.K. Ge ${ }^{1}$, Y.B. Li ${ }^{1}$, S.S. Wang ${ }^{1}$, H. Zhang ${ }^{1}$, L. Zhang ${ }^{1}$, Y.F. Liu ${ }^{1}$ and H. Liu ${ }^{2}$ \\ ${ }^{1}$ School of Water Conservancy, North China University of Water Resources and Electric Power; Henan Key Laboratory of \\ Water-saving Agriculture, Zhengzhou, China \\ ${ }^{2}$ Ministry of Agriculture and Rural Affairs / Farmland Irrigation Research Institute, Chinese Academy of Agricultural \\ Sciences, Xinxiang, China
}

\begin{abstract}
Summary
Modelling of crop transpiration and soil evaporation separately is important to estimate crop evapotranspiration (ET) for achieving high yield and efficient water use. The Shuttleworth-Wallace (SW) model can estimate crop transpiration/soil evaporation partitioning in sparse farmland, but its applicability in a solar greenhouse needed exploring. Here, greenhouse tomato under drip irrigation was used to estimate daily crop transpiration, soil evaporation and crop ET $_{\mathrm{c}}$ using the $S W$ model over two years. The measured values were obtained from a sap flow system, micro-lysimeters and weighing lysimeters during the growing period. An improved SW model (ISW) was proposed in response to the estimation error at the vegetative stage. Results showed that daily variations in estimated crop transpiration, soil evaporation, and crop $\mathrm{ET}_{c}$ from the SW model were similar to the measurements. However, the SW model overestimated crop $\mathrm{ET}_{\mathrm{c}}$ by $30.8 \%$ when leaf area index (LAI) was less than 0.5 and underestimated crop $\mathrm{ET}_{\mathrm{c}}$ by $12.9 \%$ when LAI was greater than 2.7 . Its accuracy was the maximum when LAI was between 0.5 and 2.7. The ISW can increase the simulation accuracy by $23 \%$ by introducing the water stress coefficient at the vegetative stage. These results can be used as the theoretical basis for optimizing the irrigation scheduling for greenhouse crops.
\end{abstract}

\section{Keywords}

stomatal resistance, sap flow system, micro-lysimeter, weighing lysimeter, drip irrigation

\section{Introduction}

Solar greenhouse is a kind of energy-saving greenhouse, which consists of gables on both sides, a maintenance rear wall, a supporting skeleton and covering materials. It has no heating system, but realizes heat storage and heat release through the rear wall to absorb solar energy, keeping the inner temperature to meet the needs of vegetable growth. Irrigation is the leading form of water supply for fruit and vegetable production in greenhouses, as there is no rainfall supplement. To ensure high yield and quality is an appropriate supply of water at the right time (Li et al., 2017; Qiu et al., 2019a). More than 99\% of irrigation water is used for crop evapotranspiration $\left(\mathrm{ET}_{\mathrm{c}}\right)$ in farmland irrigation (Kool

\section{Significance of this study}

What is already known on this subject?

- Crop evapotranspiration is an important indicator for crop irrigation schedule, especially in greenhouses, as there is no rainfall supplement.

What are the new findings?

- The performance of the dual source model was evaluated, firstly related to leaf area index, and secondly to canopy resistance.

What is the expected impact on horticulture?

- Estimating plant transpiration and soil evaporation separately is essential to develop an accurate irrigation schedule, and is also important for yield and quality.

et al., 2014). Therefore, the key requirement to achieve regular quantitative supplementary irrigation is to master the regularity of crop $\mathrm{ET}_{\mathrm{c}}$ in the greenhouse. Soil evaporation cannot be ignored when defining crop $\mathrm{ET}_{c^{\prime}}$ A previous study has shown that the ratio of soil evaporation to $\mathrm{ET}_{\mathrm{c}}\left(\mathrm{E}_{\mathrm{ET}} \mathrm{E}\right)$ in cabbage and radish greenhouse crops was $39.8 \%$ and $38.5 \%$, $58.2 \%$ and $48.2 \%, 32.1 \%$ and $29.1 \%$, and $28.8 \%$ and $62.0 \%$ for the whole growing period, and seedling, middle, and late stages, respectively (Liu et al., 2008, 2009). For greenhouse tomato, the $\mathrm{E} / \mathrm{ET}_{\mathrm{c}}$ was the highest at the vegetative stage and reached $24.0 \%$ throughout the growing cycle (Gong et al., 2017a). Overall, soil evaporation account for a considerable proportion of $\mathrm{ET}_{\mathrm{c}}$. However, previous studies on $\mathrm{ET}_{\mathrm{c}}$ have mainly focused on crop transpiration, while ignoring soil evaporation, especially in the case of greenhouse production (Medrano et al., 2005; Qiu et al., 2013). Therefore, the estimation results of $\mathrm{ET}_{\mathrm{c}}$ may be biased, especially during the vegetative stage when the soil surface was bare.

Instrument-based monitoring and numerical simulation are the two main methods for obtaining $\mathrm{ET}_{c}$, but the former is often limited by measurement errors (Zhang et al., 2008). Therefore, an accurate mathematical model to estimate ET is necessary to effectively solve this problem. Penman-Monteith (PM) model was often used to calculate crop $\mathrm{ET}_{\mathrm{c}}$. The model performs well in densely vegetated canopies (Ortega-Farias et al., 2004; Yan et al., 2015). However, it cannot effectively discriminate between soil and crop water consumption, as it treats both canopy and soil surface as a big leaf. Therefore, soil evaporation is essentially ignored, re- 
sulting in the underestimation of $\mathrm{ET}_{\mathrm{c}}$ magnitude (Kato et al., 2004; Qiu et al., 2019b). The dual crop coefficient method has also been often used to estimate crop $\mathrm{ET}_{\mathrm{c}}$ in greenhouse spaces. The method includes reference crop evapotranspiration, basal crop coefficient and soil evaporation coefficient. Owing to its simplicity and accuracy, this method has been widely used in estimating $\mathrm{ET}_{\mathrm{c}}$ for different types of crops and climatic regions (Yang et al., 2016; Zhao et al., 2015). However, it is difficult to choose the crop coefficient and reference crop evapotranspiration to estimate soil evaporation and plant transpiration for soil-grown crops in a solar greenhouse, especially at different growth stages. To solve the problem of estimating soil evaporation and plant transpiration under sparse vegetation conditions, the dual source model was constructed by Shuttleworth and Wallace (1985) by referring to the single-source PM model theory. The Shuttleworth-Wallace model (SW) cannot only estimate the total amount of $\mathrm{ET}_{\mathrm{c}}$ better, but can also distinguish between different processes of soil evaporation and plant transpiration (Juhász and Hrotkó, 2014). Previous studies have described the results of the SW model applied to vineyards (Zhao et al., 2015), orchards (Liu et al., 2013a), row-crops (Gardiol et al., 2003), and clumping crops (Yang and Song, 2012). In these cases, the simulation results were in good agreement with the measurements.

In spite of the numerous reports on the applicability of the SW model, it is necessary to further study whether the SW model is suitable under the conditions of exposed soil and crop canopy in a solar greenhouse. In addition, a certain degree of water stress was needed to promote tomato root growth at the vegetative stage (Gong et al., 2017b). Iritz et al. (1999) indicated that the accuracy of the SW model will be weakened under water stress conditions. In FA056, the effect of soil water stress on crop $\mathrm{ET}_{\mathrm{c}}$ was reflected by the reduction in the crop coefficient value in the double crop-coefficient method, which can be expressed as the product of crop coefficient and water stress coefficient (Ding et al., 2013). Whether the water stress coefficient can be introduced into the SW model to achieve a more accurate crop ET under water deficit conditions at vegetative stage required further study.

Therefore, the objectives of this study were to: (1) evaluate the applicability of the SW model in a solar greenhouse; (2) improve its accuracy at the vegetative stage.

\section{Materials and methods}

\section{Experimental site and design}

The experiments were performed from March to July 2015 and 2016 in the Comprehensive Experimental Station of Xinxiang (35 ${ }^{\circ}{ }^{\prime} \mathrm{N}, 113^{\circ} 5^{\prime} \mathrm{E}$, at an altitude of $78.7 \mathrm{~m}$ a.s.l.). The annual precipitation, potential evaporation and mean air temperature were $550 \mathrm{~mm}, 1,910 \mathrm{~mm}$ and $14.5^{\circ} \mathrm{C}$, respectively. The greenhouse covers an area of $510 \mathrm{~m}^{2}$ (60 m long and $8.5 \mathrm{~m}$ wide), and is covered with $0.2 \mathrm{~mm}$ thick thermal polyethylene sheet. The greenhouse was constructed using a steel-frame structure, and oriented in the east-west direction, and the crops were planted in the north-south direction for better interception of sunlight. It has no other heating and cooling system, while it uses vents on the top and south to regulate the microclimate inside the greenhouse. The experimental soil was silt loam with a mean bulk density of $1.51 \mathrm{~g} \mathrm{~cm}^{-3}$, field soil water capacity of $0.366 \mathrm{~cm}^{3} \mathrm{~cm}^{-3}$ and wilting point water content of $0.09 \mathrm{~cm}^{3} \mathrm{~cm}^{-3}$.

The planting pattern of tomato (Lycopersicon esculentum
Mill. 'Jingding') was wide and narrow row planting (65 and $45 \mathrm{~cm}$, respectively). The planting density was 5.7 plants $\mathrm{m}^{-2}$. Transplanting of tomato seedlings was performed on March 10, 2015, and March 9, 2016. Drip irrigation was used throughout the growing period. A D-20 pan placed $30 \mathrm{~cm}$ above the canopy at the centre of the greenhouse was used to guide irrigation time and quantity. Irrigation was conducted when the cumulative pan evaporation reached $20 \mathrm{~mm}$ (Gong et al., 2019). Twenty $\mathrm{mm}$ of water was applied to ensure a high seedling survival rate after transplanting. During the experimental period, agronomic measures were similar to the local.

\section{Meteorological measurements}

Solar radiation, net radiation, air temperature, relative humidity and air speed were measured simultaneously. The corresponding sensors were as follows: radiometer (LI200X; Campbell Scientific, Inc., USA), net radiometer (NR LITE2; Kipp \& Zonen, Delft, The Netherlands), temperature and relative humidity recorder (CS215, Campbell Scientific, Inc., USA), and air velocity meter (Wind Sonic, Gill, UK), respectively. These sensors were placed at a height of $2.0 \mathrm{~m}$ at the centre of the greenhouse. The CR-1000 data logger (Campbell Scientific Inc., USA) was used to collect data every $30 \mathrm{~min}$.

\section{Measurement of crop evapotranspiration, transpiration and evaporation}

Two weighing lysimeters located at the centre of the greenhouse were used to measure crop ET ${ }_{\mathrm{c}}$ from March 10 to July 15,2016 . The maximum range of the weighing lysimeter was 2.5 tons with a precision of $0.01 \mathrm{~kg}$. A microcomputer collected the data every $1 \mathrm{~h}$. Six tomatoes were planted in each weighing lysimeter, and the planting pattern was consistent with the outer lysimeter. To avoid interferences, all the six plants were supported by bamboo sticks.

A sap flow system (Flow32-1k system; Dynamax, Houston, TX, USA) was used to measure transpiration from May 15 to July 15, 2015 and from April 14 to July 10, 2016. Eight healthy plants located at centre of the greenhouse were randomly selected. The SGA9-WS/SGA10-WS and SGB12-WS gauges were used to measure sap flow after measuring the stem diameter. To avoid the effect of surface heat-flux on the temperature change of stem, these gauges were fixed above the cotyledons. Sap flow data were recorded every $30 \mathrm{~min}$ using the CR-1000 data logger (Campbell Scientific Inc., USA).

The micro-lysimeters were used to measure daily soil evaporation during throughout the cropping season. They were made of iron sheet and consisted of an inner and outer cylinder of diameters 10 and $12 \mathrm{~cm}$, respectively, and the height was $15 \mathrm{~cm}$. Detailed measurements of soil evaporation can be found in Gong et al. (2017b). To improve measurement accuracy, the soil in the inner cylinder needs to be replaced every two days after irrigation. Twelve replications were carried out.

\section{Other measurements}

1. Soil moisture. Five ECH2O sensors (5TE; Decagon Devices, Inc., USA) were used to monitor soil moisture at 10, 20, 30,40 , and $60 \mathrm{~cm}$ below the soil surface continuously, using the EM50 data-logger (Decagon Devices, Inc., USA) to collect data every $1 \mathrm{~h}$. The measuring position of soil moisture content under drip irrigation was at a distance of $15 \mathrm{~cm}$ from the drippers along rows (Impron et al., 2008). Three replications were set and the average value of the three replications was calculated. 
2. Crop height and leaf area. They were measured using a ruler. The measurements were made from the surface of soil to the top of the canopy. The leaf area of tomato was obtained by measuring the leaf length and maximum width, and the conversion coefficient of 0.644 for the leaf area was derived from fitting the measured results to the one drawn using CAD software.

3. Leaf stomatal resistance. A leaf porometer (SC-1; Decagon Devices Inc., USA) was used directly to measure leaf stomatal resistance. Functional leaves of 6-9 healthy plants were randomly selected at 7-10 d intervals for measurement. After irrigation, the measurement was carried out every day, and then diurnal variation was monitored at each growth stage.

\section{Theoretical model}

\section{Shuttleworth-Wallace model}

The Shuttleworth-Wallace (SW) model combines two one-dimensional models of soil evaporation and plant transpiration. The two one-dimensional models can be expressed as follows (Shuttleworth and Wallace, 1985):

$$
\begin{aligned}
& \lambda E T=\lambda E+\lambda T=C_{s} P M_{S}+C_{c} P M_{c} \\
& P M_{S}=\frac{\Delta A_{c}+\left\{\left[\rho_{a} c_{p} V P D-\Delta r_{a}^{s}\left(A_{c}-A_{s}\right)\right] /\left(r_{a}^{a}+r_{a}^{s}\right)\right\}}{\Delta+\gamma\left[1+r_{s}^{s} /\left(r_{a}^{a}+r_{a}^{s}\right)\right]} \\
& P M_{c}=\frac{\Delta A_{c}+\left[\rho_{a} c_{p} V P D-\Delta r_{a}^{c} A_{s}\right] /\left(r_{a}^{a}+r_{a}^{c}\right)}{\Delta+\gamma\left[1+r_{s}^{c} /\left(r_{a}^{a}+r_{a}^{c}\right)\right]} \\
& C_{S}=\left[1+R_{S} R_{a} / R_{c}\left(R_{S}+R_{a}\right)\right]^{-1} \\
& C_{C}=\left[1+R_{c} R_{a} / R_{S}\left(R_{c}+R_{a}\right)\right]^{-1}
\end{aligned}
$$

where $\lambda$ is the latent heat flux of vaporisation $\left(\mathrm{J} \mathrm{kg}^{-1}\right) ; \gamma$ is the psychrometric constant $(\mathrm{kPa} / \mathrm{K})$; $\mathrm{E}$ and $\mathrm{T}$ are soil evaporation and plant transpiration, respectively; $\Delta$ is the slope of saturation vapor pressure curve $(\mathrm{kPa} / \mathrm{K}) ; \rho_{a}$ is the air density $\left(\mathrm{kg} \mathrm{m}^{-3}\right)$; VPD is water vapor deficit $(\mathrm{kPa}) ; r_{a}^{s}$ and $r_{a}^{a}$ are aerodynamic resistance from the soil surface to canopy surface and from there to the reference height $(\mathrm{s} / \mathrm{m})$, respectively; $r_{s}^{c}$ and $r_{a}^{c}$ are bulk resistance of canopy and boundary layer $(\mathrm{s} / \mathrm{m})$, respectively; $r_{s}^{s}$ is the soil surface resistance $(\mathrm{s} / \mathrm{m})$; $A_{c}$ and $A_{s}$ are the available energy to canopy and soil surface (W $\mathrm{m}^{-2}$ ), respectively, and it can be expressed as $A_{c}=R_{n}-G$, $A_{s}=R_{n s}-G$. The partitioning of the $R_{n}$ and the $R_{n s}$ was determined using Beer's law (Iritz et al., 1999). The $R_{a}, R_{s}$ and $R_{c}$ are expressed as follows:

$$
\begin{aligned}
& R_{a}=(\Delta+\gamma) r_{a}^{a} \\
& R_{s}=(\Delta+\gamma) r_{a}^{s}+\gamma r_{s}^{s} \\
& R_{c}=(\Delta+\gamma) r_{a}^{c}+\gamma r_{s}^{c}
\end{aligned}
$$

where these symbols have the same meaning as above.

\section{Aerodynamic resistance}

The $r_{\mathrm{a}}^{\mathrm{a}}$ and $r_{\mathrm{a}}^{\mathrm{s}}$ were calculated as reported by Shuttleworth and Wallace (1985). The $r_{\mathrm{a}}^{\mathrm{c}}$ was closely related to LAI (Juhász and Hrotkó, 2014), and it can be calculated as follows:

$$
r_{a}^{c}=\frac{r_{b}}{2 L A I}
$$

where $r_{\mathrm{b}}$ is the mean boundary layer resistance per unit surface area of crop (s/m), taken as 235 s/m (Lei et al., 2004).

\section{Surface resistance}

The $r_{s}^{c}$ can be obtained by the ratio of leaf stomatal resistance $\left(r_{\mathrm{sT}}\right)$ to effective leaf area index $\left(\mathrm{LAI}_{e}\right)$ (Qiu et al., 2013), it can be expressed as follows:

$$
r_{s}^{c}=\frac{r_{s T}}{L A I_{e}}
$$

The values of $\mathrm{LAI}_{e}$ are as follows: $\mathrm{LAI}_{e}$ and $\mathrm{LAI}$ are equivalent when $\mathrm{LAI} \leq 2, \mathrm{LAI}_{e}$ is equal to 2 when $2<\mathrm{LAI}<4$, and $\mathrm{LAI}_{e}$ is equal to $\mathrm{LAI} / 2$ when $\mathrm{LAI} \geq 4$ (Gardiol et al., 2003).

The $r_{\mathrm{s}}^{\mathrm{s}}$ was estimated according to the model suggested by Anadranistakis et al. (2000), and it can be expressed as:

$$
r_{s}^{s}=r_{s m i n}^{s} f\left(\theta_{s}\right)=r_{s m i n}^{s}\left(2.5 \frac{\theta_{F S}}{\theta_{s}}-1.5\right)
$$

where $r_{\mathrm{s} \text { min }}^{\mathrm{s}}$ is the minimum soil surface resistance, taken as $100 \mathrm{~s} / \mathrm{m}$ (Li et al., 2013). $\theta_{\mathrm{FS}}$ is the field capacity at $10 \mathrm{~cm}$ depth $\left(\mathrm{m}^{3} \mathrm{~m}^{-3}\right) ; \theta_{\mathrm{s}}$ is the soil water content at $10 \mathrm{~cm}$ depth $\left(\mathrm{m}^{3} \mathrm{~m}^{-3}\right)$. Top soil moisture was measured using a gravimetric method every day.

\section{Evaluation of model performance}

The coefficient of determination $\left(R^{2}\right)$, mean absolute error (MAE), root mean square error (RMSE), and index of agreement $\left(d_{1}\right)$ were used to evaluate the consistency of the model according to the following equations (Willmott and Matsuura, 2005):

$$
\begin{aligned}
& R^{2}=\left\{\frac{\sum_{i=1}^{N}\left(O_{i}-\bar{O}\right)\left(P_{i}-\bar{P}\right)}{\sqrt{\left(O_{i}-\bar{O}\right)^{2}} \sqrt{\left(P_{i}-\bar{P}\right)^{2}}}\right\} \\
& M A E=\sum_{i=1}^{N}\left|O_{i}-P_{i}\right| / \mathrm{N} \\
& R M S E=\left[\sum_{i=1}^{N}\left(O_{i}-P_{i}\right)^{2} / N\right]^{0.5} \\
& d_{l}=1-\sum_{i=1}^{N}\left(O_{i}-P_{i}\right)^{2} / \sum_{i=1}^{N}\left(\left|P_{i}-\bar{O}\right|+\left|O_{i}-\bar{O}\right|\right)^{2}
\end{aligned}
$$

where $P_{i}$ and $O_{i}$ are the calculated and measured values, respectively; $\bar{P}$ and $\bar{O}$ are the mean values of the measured values. $N$ is the number of the paired set data.

\section{Results}

\section{Microclimate parameters in the solar greenhouse}

Daily net radiation and pan evaporation on most days during the experimental period ranged between 1.40-14.90 MJ m ${ }^{-2} \mathrm{~d}^{-1}$ and $0.3-7.8 \mathrm{~mm}$ in 2015, and between 0.27-15.15 MJ $\mathrm{m}^{-2} \mathrm{~d}^{-1}$ and $0.1-5.5 \mathrm{~mm}$ in 2016, respectively (Figure 1). Atmospheric conditions in the greenhouse were relatively moist, with average values of air temperature, relative humidity and vapor pressure deficit of $22.97^{\circ} \mathrm{C}, 74.86 \%$ and $0.76 \mathrm{kPa}$ in 2015 , and $22.84^{\circ} \mathrm{C}, 74.89 \%$ and $0.72 \mathrm{kPa}$ in 2016 , respectively (Figure 1). Maximum pan evaporation was measured in June; maximum diurnal air temperature and vapor pressure deficit were $31.74{ }^{\circ} \mathrm{C}$ and $2.46 \mathrm{kPa}$, respectively.

\section{Variations in soil evaporation to crop evapotranspiration ratio and LAI}

Figure 2 shows the changes in soil evaporation to crop evapotranspiration ratio $\left(\mathrm{E} / \mathrm{ET}_{\mathrm{c}}\right)$ and LAI throughout the growing period. The trend of change in $\mathrm{E} / \mathrm{ET}_{\mathrm{c}}$ and LAI was opposite; the $\mathrm{E}_{\mathrm{ET}} \mathrm{c}$ decreased significantly with increase in 
LAI, and the E/ET ${ }_{\mathrm{c}}$ changed from 0.21 to 0.97 , with an average of 0.59 . This is because the LAI of tomato seedlings was small, and the ground coverage was lower. As plants entered the flowering stage, the LAI gradually increased, leading to a decrease in the $\mathrm{E} / \mathrm{ET}_{\mathrm{c}}$, which varied between 0.03 and 0.32 , with an average value of 0.18 . At the fruit-setting and picking stages, the LAI peaked and the E/ET ${ }_{c}$ was very small. At this stage, the $\mathrm{E} / \mathrm{ET}_{\mathrm{c}}$ varied between 0.01 and 0.35 , with an average value of 0.11 . Additionally, as the soil surface was wet af- ter irrigation, soil evaporation increased significantly; under such conditions, the average value of $\mathrm{E} \mathrm{ET}_{\mathrm{c}}$ was close to 0.29 .

\section{Determination of stomatal and canopy resistances}

The value of stomatal resistance $\left(r_{\mathrm{sT}}\right)$ needs to be measured accurately when calculating canopy resistance $\left(r_{\mathrm{s}}^{\mathrm{c}}\right)$. Several studies have shown that the change in the $r_{\mathrm{ST}}$ was mainly affected by solar radiation $\left(R_{\mathrm{s}}\right)$ (Qiu et al., 2013; Zhao et al., 2015; Juhász and Hrotkó, 2014). Figure 3 shows that

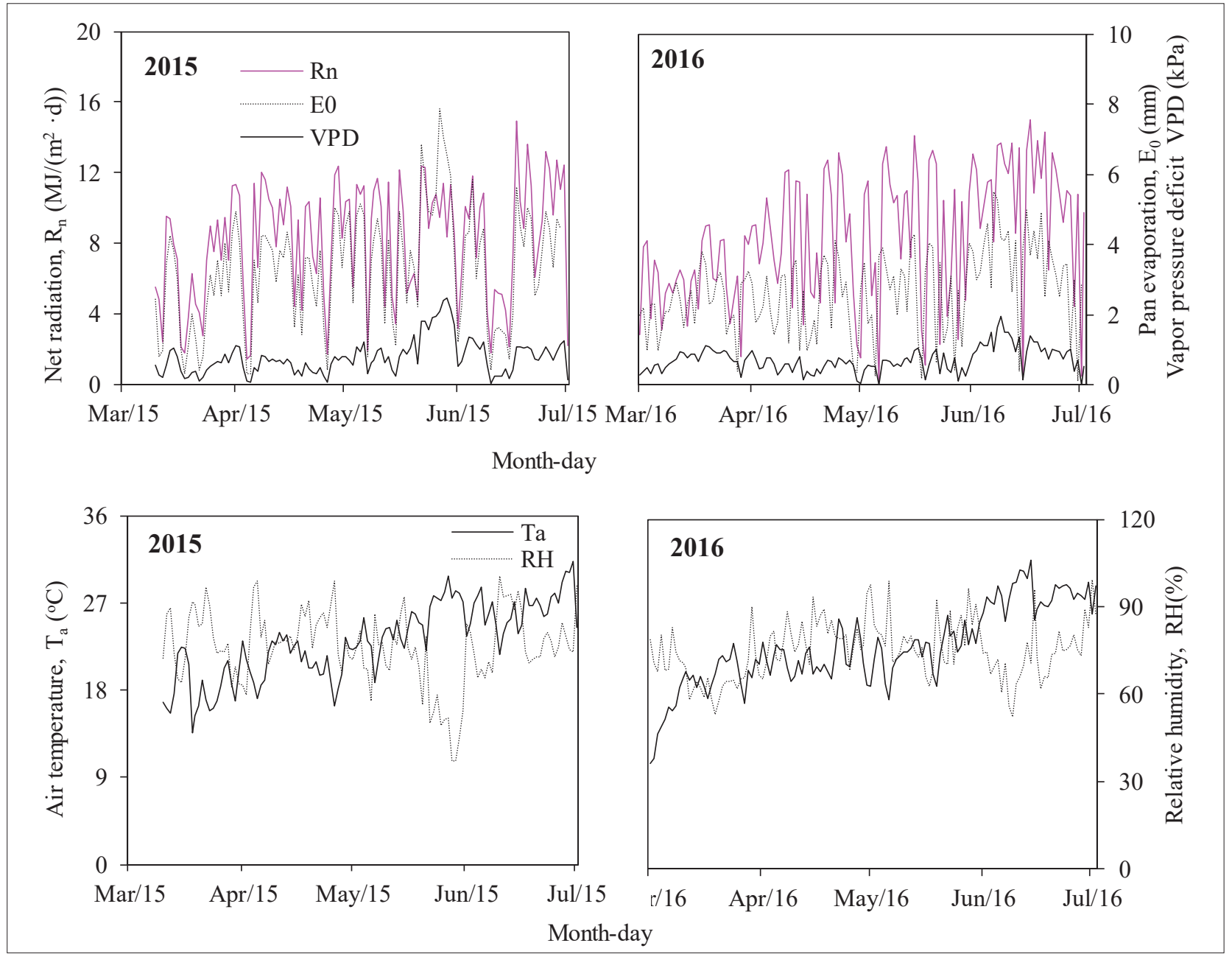

FIGURE 1. Variations of net radiation $\left(R_{n}\right)$, pan evaporation $\left(E_{0}\right)$, air temperature $\left(T_{a}\right)$, relative humidity (RH), and vapor pressure deficit (VPD) in the solar greenhouse during the growing period in two study years.

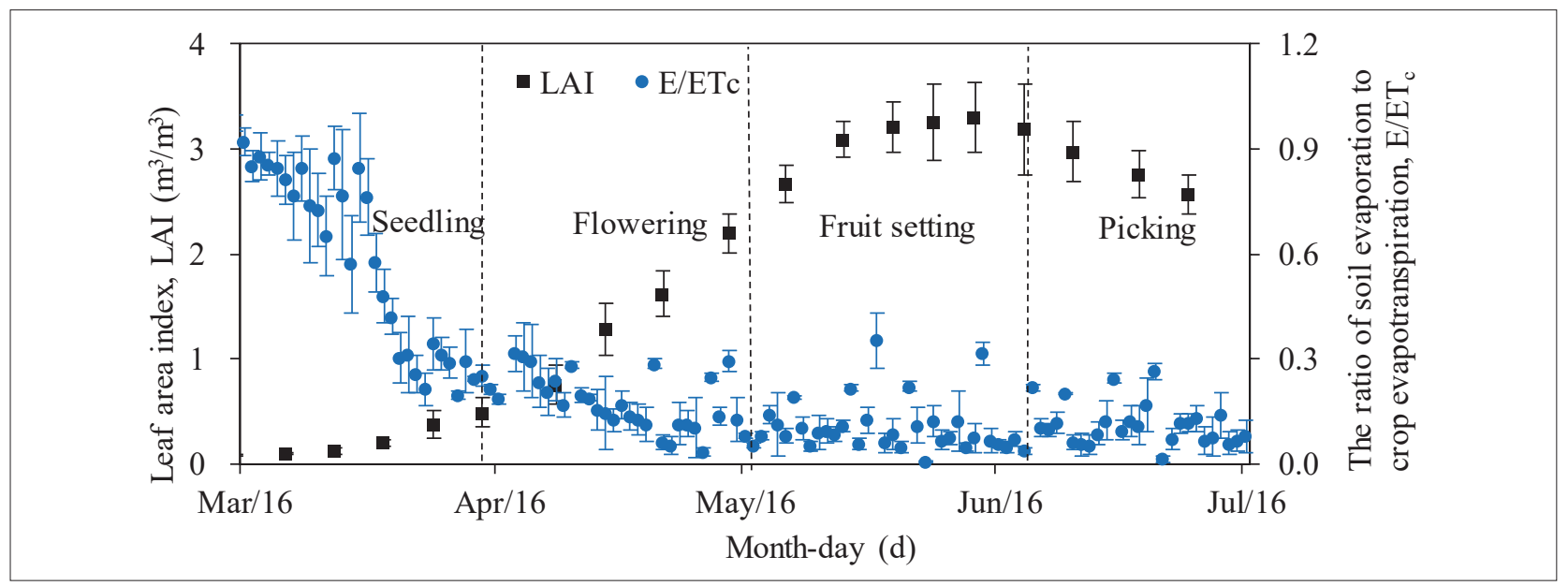

FIGURE 2. Changes in the E/ET ratio and LAI throughout the tomato growth period in 2016. 


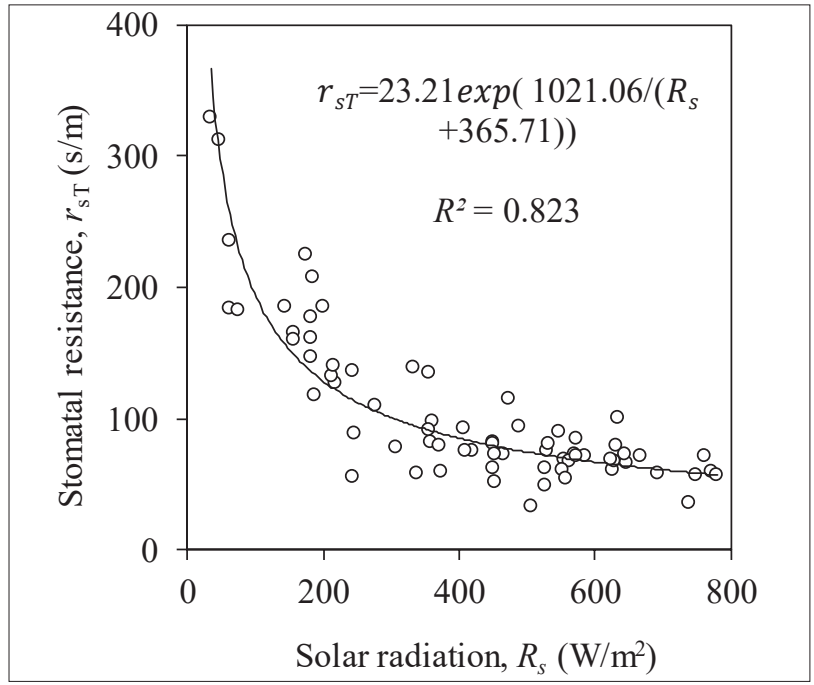

FIGURE 3. Relationship between leaf stomatal resistance $\left(r_{\mathrm{sT}}\right)$ and solar radiation $\left(R_{\mathrm{s}}\right)$.

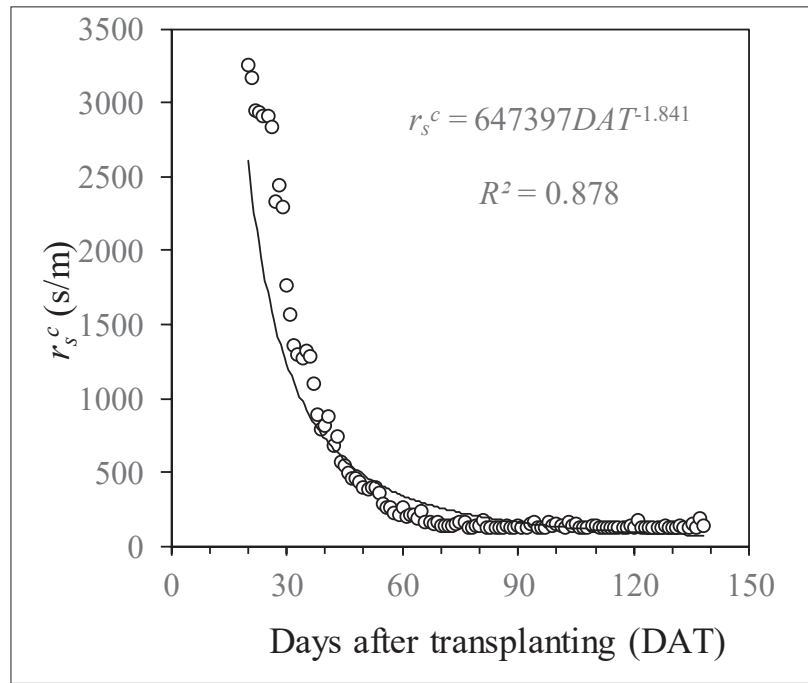

FIGURE 4. Relationship between canopy resistance $\left(r_{\mathrm{s}}^{\mathrm{c}}\right)$ and days after transplanting (DAT).

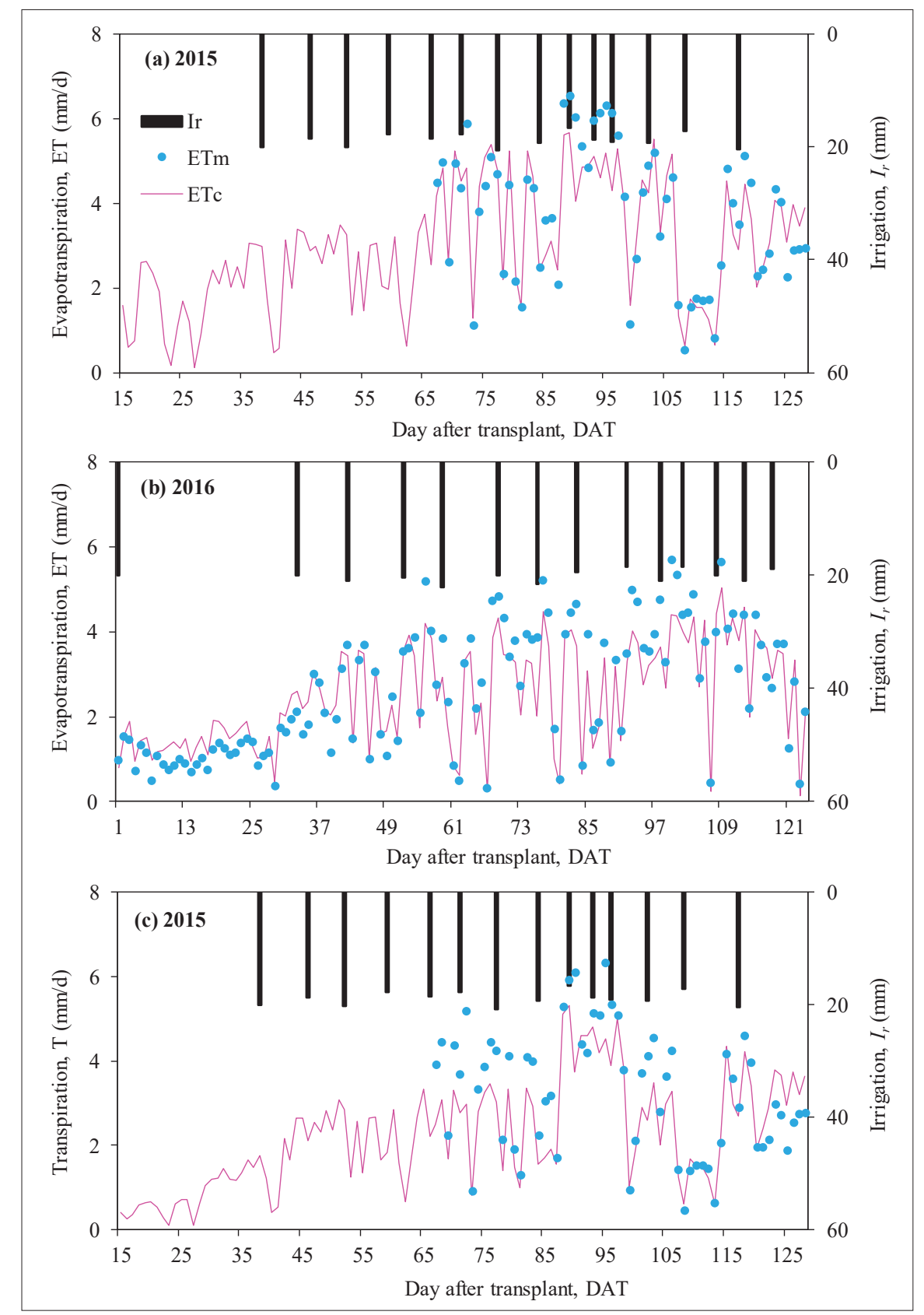


the variation in $r_{\mathrm{sT}}$ with $R_{\mathrm{s}}$ can be fitted with an exponential function. From the fitting of 70 sets of data, the correlation coefficient is 0.823 . The $r_{\mathrm{sT}}$ decreased significantly with the increase in $R_{\mathrm{s}}$, and the minimum value of $r_{\mathrm{sT}}\left(33.5 \mathrm{~s} \mathrm{~m}^{-1}\right)$ was obtained when $R_{\mathrm{s}}$ reached around $780 \mathrm{~W} \mathrm{~m}^{-2}$. Conversely, the maximum value of $r_{\mathrm{sT}}\left(330 \mathrm{~s} \mathrm{~m}^{-1}\right)$ was obtained when $R_{\mathrm{s}}$ reduced around $33.5 \mathrm{~W} \mathrm{~m}^{-2}$.
From previous studies (Yan et al., 2018), the $r_{\mathrm{s}}^{\mathrm{c}}$ and days after transplanting (DAT) have a certain correlation. In our study, we also found that the DAT was the most correlated factor with the $r_{\mathrm{s}}^{\mathrm{c}}$ after comparing other meteorological factors (se.g., $R_{s}, T_{a}$, RH and VPD). The relationship between the $r_{s}{ }^{\mathrm{c}}$ and DAT can be expressed by a power function (Figure 4). From the fitting of 148 sets of data, the correlation coefficient

TABLE 1. Statistical results of daily $\mathrm{ET}_{{ }^{\prime}}$, $\mathrm{E}$ and $\mathrm{T}$ estimates obtained using the $\mathrm{SW}$ model and measured values during the tomato cropping seasons in two study years.

\begin{tabular}{lcccccccc}
\hline Index & $b$ & $R^{2}$ & MAE & RMSE & $d_{1}$ & $\overline{0}$ & $\bar{P}$ & $\mathrm{~N}$ \\
\hline$E T_{c}$ & 0.93 & 0.87 & 0.44 & 0.31 & 0.96 & 2.97 & 2.71 & 186 \\
$E$ & 0.98 & 0.48 & 0.16 & 0.07 & 0.82 & 0.45 & 0.48 & 229 \\
$T$ & 0.85 & 0.81 & 0.60 & 0.59 & 0.92 & 3.13 & 2.13 & 145 \\
\hline
\end{tabular}

$R^{2}$ is the coefficient of determination; MAE is the mean absolute error $(\mathrm{mm})$; RMSE is the root mean square error ( $\left.\mathrm{mm}\right)$; $d_{l}$ is the index of agreement; $\bar{O}$ is the mean of measurements using the weighing lysimeters $(\mathrm{mm}) ; \bar{P}$ is the mean value estimated using the SW model (mm); N is the number of samples.

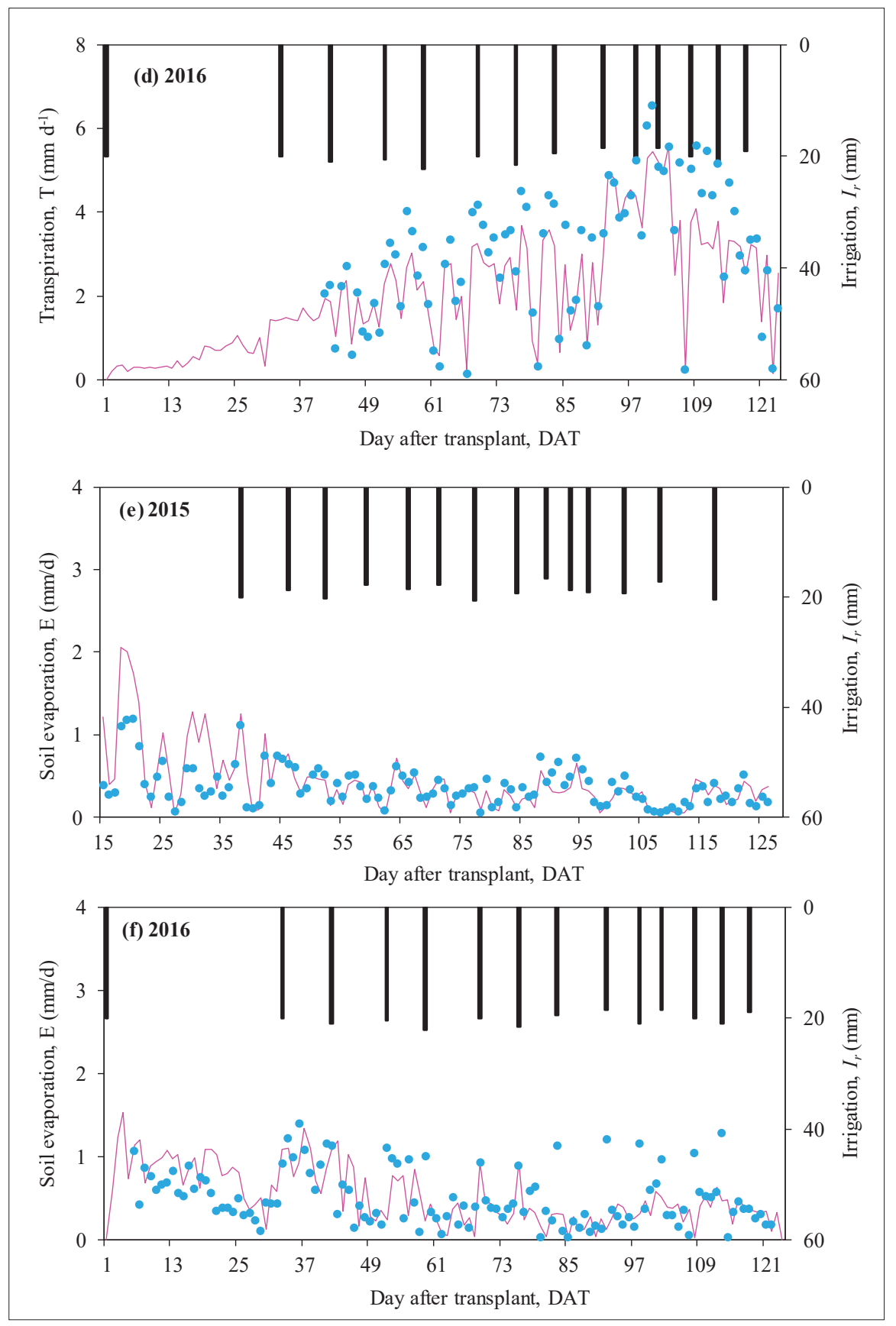

FiguRE 5. Comparison of daily measured values and SW model estimates for evapotranspiration, transpiration and soil evaporation during the tomato cropping seasons in two study years. 
is 0.878. The $r_{\mathrm{sT}}$ declined along with DAT, and daily maximum value of $r_{\mathrm{s}}^{\mathrm{c}}$ obtained in present study was around 3,500 $\mathrm{s} \mathrm{m}^{-1}$, and decreased to lower than $200 \mathrm{~s} \mathrm{~m}^{-1}$ after 65 DAT. This is different from the results of Yan et al. (2018) (the maximum and minimum values of $r_{\mathrm{s}}^{\mathrm{c}}$ are lower than in this study).

\section{Performance of the SW model in a solar greenhouse}

Daily plant transpiration, soil evaporation and crop ET were calculated using the SW model on data recorded hourly during the growing season. Comparison and correlation of daily $\mathrm{ET}_{\mathrm{c}}$ between values estimated using the SW model and values measured using the weighing lysimeters in two study years are summarized in Figures 5 and 6, and Table 1. Figure $5 \mathrm{a}, \mathrm{b}$ shows the estimation results of daily $\mathrm{ET}_{\mathrm{c}}$. Estimates of daily $\mathrm{ET}_{\mathrm{c}}$ using the SW model were in good agreement with the actual measurements. However, the daily $\mathrm{ET}_{\mathrm{c}}$ was overestimated and underestimated at the vegetative stage and after irrigation, respectively. The main reasons were very likely the large, exposed soil-surface area the vegetative stage and the sharp increase of soil evaporation after irrigation. The SW model slightly underestimated the daily $\mathrm{ET}_{\mathrm{c}}$ by
$3.6 \%$ and $3.0 \%$ in 2015 and 2016, respectively, throughout the growth cycle (slope of the regression equation was 0.93). The mean absolute error (MAE) was $0.44 \mathrm{~mm} \mathrm{~d}^{-1}$, root mean square error (RMSE) was $0.31 \mathrm{~mm} \mathrm{~d}^{-1}$ and the index of agreement $\left(d_{1}\right)$ was 0.96 for the two growing seasons (Table 1 ). This was mainly reflected in both the slight overestimation during the seedling period and the slight underestimation during the period of high canopy coverage. For example, the SW model overestimated the daily $\mathrm{ET}_{\mathrm{c}}$ by $30.8 \%$ when the LAI was less than 0.5 at the vegetative stage. Conversely, the SW model underestimated the daily $\mathrm{ET}_{\mathrm{c}}$ by $12.9 \%$ when the LAI was greater than 2.7 at the fruiting period. The simulation precision of the SW model was the maximum when the LAI was between 0.5 and 2.7 .

Figure 5c, d shows that daily crop transpiration was obviously underestimated by the SW model, throughout the growing cycle, by $12.8 \%$ and $13.8 \%$ in 2015 and 2016, respectively (slope of the regression equation was 0.85 , Figure 6b). The MAE, RMSE and $d_{1}$ were $0.60 \mathrm{~mm} \mathrm{~d}^{-1}, 0.59$ $\mathrm{mm} \mathrm{d}^{-1}$ and 0.92 during the two cropping cycles (Table 1). Figure $5 \mathrm{e}$, $\mathrm{f}$ shows the estimation results of daily soil
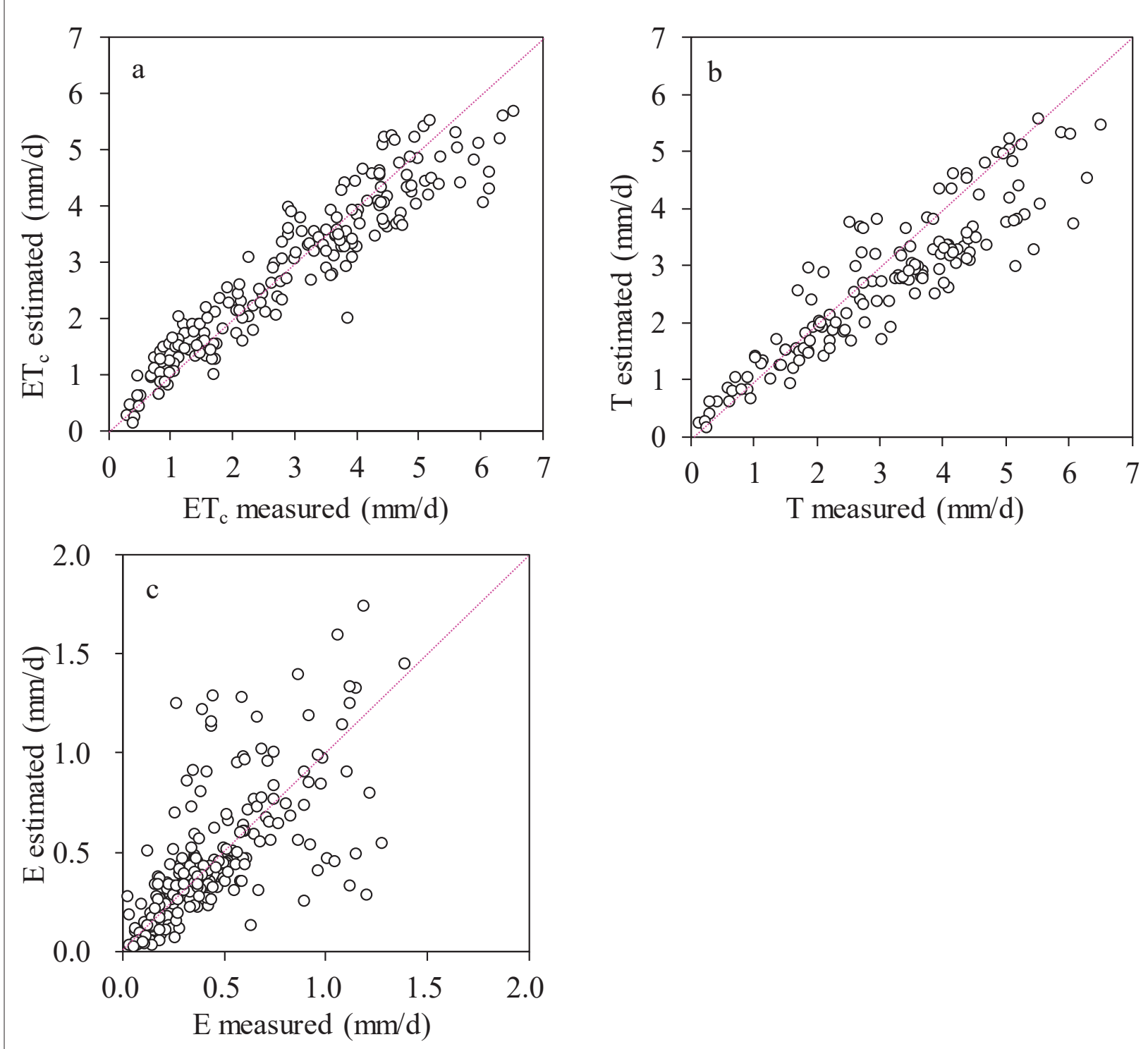

FigurE 6. Comparison of daily $\mathrm{ET}_{c}, \mathrm{E}$ and $\mathrm{T}$ between the estimates obtained using the $\mathrm{SW}$ model and measured values during the tomato cropping seasons in two study years. 
evaporation. The bias of the SW model mainly occurred during the vegetative stage and irrigation period. Soil evaporation was overestimated and underestimated at the vegetative stage and after irrigation events, respectively. The SW model slightly underestimated daily soil evaporation by $11.5 \%$ and $1.1 \%$ in 2015 and 2016 , respectively, over the whole cropping cycle (slope of the regression equation was 0.98 , Figure $6 \mathrm{c}$ ). The MAE, RMSE and $d_{1}$ were $0.16 \mathrm{~mm} \mathrm{~d}^{-1}$, $0.07 \mathrm{~mm} \mathrm{~d}^{-1}$ and 0.82 during the two study periods (Table 1).

\section{Discussion}

Canopy and soil surface resistance are both introduced in the SW model, thus it can generate better estimates of plant transpiration and soil evaporation. However, the simulation results obtained by using the SW model in a solar greenhouse were unstable, especially at the vegetative stage. The reasons for the overestimation of $\mathrm{ET}_{\mathrm{c}}$ using the SW model are as follows. Firstly, the energy of the canopy intercepted may be overestimated using the SW model at the seedling stage (Zhang et al., 2008), especially when the LAI was less than 0.5 . Secondly, only $20 \mathrm{~mm}$ water was supplied after transplant to enhance the root system of tomato plants at the vegetative stage. No irrigation was supplied before flowering stage, whereby water stress conditions may develop (Liu et al., 2013b; Yuan and Kang, 2001). Although the effect of water stress on canopy surface resistance was not considered in this study, it is true that this parameter may be underestimated under such conditions. Among all other variables included, canopy resistance was the most sensitive to the SW model (Li et al., 2013; Zhao et al., 2015). Therefore, the key to improve the accuracy of simulation with the SW model was to build the canopy resistance model (Ortega-Farias et al., 2007). Several studies have also proved this point, e.g., Anadranistakis et al. (2000) and Gardiol et al. (2003). In addition, Li et al. (2013) showed that several crops generally have to withstand water deficit condition during the seedling stage. The canopy surface resistance was often easily underestimated during this period (Yan et al., 2018). Underestimation of crop transpiration using the SW model was the main reason of the underestimation of $\mathrm{ET}_{\mathrm{c}^{*}}$ Juhász and Hrotkó (2014) reported that compared with the measurements obtained using the sap flow system,

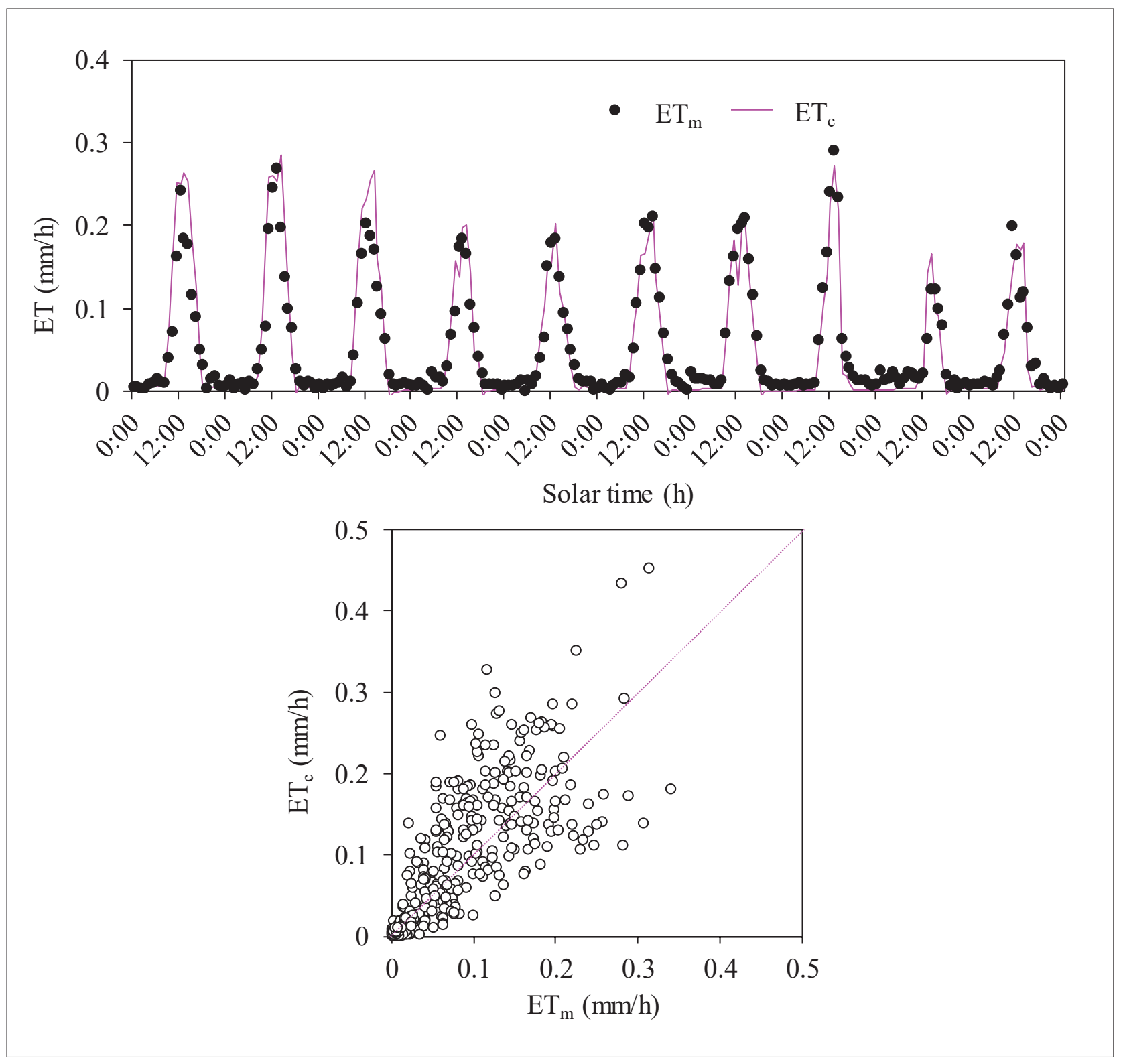

FIGURE 7. Comparison of hourly $\mathrm{ET}_{\mathrm{c}}$ between the estimated values using the ISW model and measured values using a weighing lysimeter at the vegetative stage. 
plant transpiration estimates obtained using the SW model were significantly underestimated, especially on rainy and sunny days with relatively high vapor pressure. Similarly, Ortega-Farias et al. (2010) indicated that the SW model underestimated $\mathrm{ET}_{\mathrm{c}}$ in a vineyard under drip irrigation in a Mediterranean semi-arid climate. In our study, the canopy coverage of tomato plants peaked at the fruiting stage, when the LAI was greater than 2.7. Tomato transpiration accounted for more than $90 \%$ of the total $\mathrm{ET}_{\mathrm{c}}$ during this time. When the soil surface was completely covered, crop transpiration was underestimated by $12.8 \sim 13.8 \%$. Thus, clearly the application of the SW model in greenhouses requires comprehensive consideration of meteorological factors, crop growth, and rhizosphere moisture. Moreover, establishing a canopy resistance model under water stress is also important to improve the accuracy of the SW model. In the experiments described herein on tomato plants grown in a solar greenhouse, the SW model performed well in estimating $\mathrm{ET}_{\mathrm{c}}$ when the LAI was between 0.5 and 2.7 .

The sensitivity of the SW model was analyzed by Zhao et al. (2015); they concluded that predicted crop transpiration was very sensitive to rhizosphere parameters, LAI, and minimum stomatal resistance. Predicted soil evaporation was sensitive to soil surface resistance and LAI. Clearly, rhizosphere parameters were more sensitive to crop $\mathrm{ET}_{c^{*}}$. In FA056, the effects of soil water stress on crop $\mathrm{ET}_{\mathrm{c}}$ were described by reducing the value of the crop coefficient (Ding et al., 2013). This was accomplished by multiplying the crop coefficient with the water stress coefficient, $K_{\mathrm{s}}$. Our study indicated that crop transpiration was underestimated due to soil water stress at the vegetative stage. Therefore, we only improved the SW model for that stage and estimated $\mathrm{ET}_{\mathrm{c}}$ under water stress by introducing the water stress coefficient $K_{\mathrm{s}^{*}}$ The expression is as follows:

$$
\lambda E T=\lambda E+K_{s} \cdot \lambda T=C_{S} P M_{S}+K_{S} \cdot C_{C} P M_{C}
$$

The value and calculation method for $K_{s}$ can be found in Gong et al. (2017a). Taking the experimental data obtained in 2016 as an example to illustrate the accuracy of the improved SW model (ISW) at the vegetative stage of tomato plants. Figure 7 compares hourly $\mathrm{ET}_{\mathrm{c}}$ estimates obtained using the ISW model with the measurements obtained using the weighing lysimeters. The estimates of hourly $\mathrm{ET}_{\mathrm{c}}$ from ISW model were in good agreement with the measurements of the lysimeters. The ISW model slightly overestimated hourly $\mathrm{ET}_{\mathrm{c}}$ by $7.8 \%$ (regression equation was as follows: $\mathrm{ET}_{\text {calculated }}=1.02$ $\mathrm{ET}_{\text {measured }}\left(\mathrm{R}^{2}=0.71, \mathrm{MAE}=0.02 \mathrm{~mm} \mathrm{~d}^{-1}, \mathrm{RMSE}=0.04 \mathrm{~mm} \mathrm{~d}^{-1}\right)$.

\section{Conclusions}

The following conclusions can be drawn from this study: 1. In the solar greenhouse used, the SW model overestimated tomato evapotranspiration by $30.8 \%$ when the LAI was less than 0.5 . Daily evapotranspiration was underestimated by $12.9 \%$ when the LAI was greater than 2.7. The precision of the SW model was the highest when the LAI was between 0.5 and 2.7 .

2. Total tomato transpiration was underestimated by $12.8 \%$ to $13.8 \%$ using the SW model, with the MAE, RMSE, and $d_{1}$ values of $0.60 \mathrm{~mm} \mathrm{~d}^{-1}, 0.59 \mathrm{~mm} \mathrm{~d}^{-1}$ and 0.92 , respectively, during the two growth stages. The SW model slightly underestimated soil evaporation; the difference in the MAE, RMSE, and $d_{1}$ values between model estimations and actual measurements was $0.16 \mathrm{~mm} \mathrm{~d}^{-1}, 0.07 \mathrm{~mm} \mathrm{~d}^{-1}$ and 0.82 during two growth stages.
3. The accuracy of the SW model was increased by $23 \%$ by introducing the prevalent water stress coefficient under the condition of water deficit during the vegetative stage.

\section{Acknowledgments}

This study has been financially supported by the Key Technologies R \& D and Promotion Program of Henan Province (192102110090), National Natural Science Foundation of China (51809094, 51579102, 51779093 and 51779259), Support plan for scientific and technological innovation team of colleges and universities in Henan Province (17IRTSTHN026).

\section{References}

Anadranistakis, M., Liakatas, A., Kerkides, P., Rizos, S., Gavanosis, J., and Poulovassilis, A. (2000). Crop water requirements model tested for crops grown in Greece. Agric. Water Manag. 45, 297-316. https:// doi.org/10.1016/S0378-3774(99)00106-7.

Ding, R.S., Kang, S.Z., Zhang, Y.Q., Hao, X.M., Tong, L., and Du, T.S. (2013). Partitioning evapotranspiration into soil evaporation and transpiration using a modified dual crop coefficient model in irrigated maize field with ground-mulching. Agric. Water Manag. 127, 85-96. https://doi.org/10.1016/j.agwat.2013.05.018.

Gardiol, J.M., Serio, L.A., and Maggiora, A.I.D. (2003). Modelling evapotranspiration of corn (Zea mays) under different plant densities. J. Hydrol. 271(1), 188-196. https://doi.org/10.1016/ S0022-1694(02)00347-5.

Gong, X.W., Liu, H., Sun, J.S., Mao, X.J., Wang, W.N., and Cui, Y.S. (2017a). Modeling evapotranspiration of greenhouse tomato under different water condition based on the dual crop coefficient method. Chinese J. Appl. Ecol. 28(4), 1255-1264 (in Chinese with English abstract).

Gong, X.W., Liu, H., Sun, J.S., Gao, Y., Zhang, X.X., Shiva, K., Zhang, H., Ma, X.J., and Wang, W.N. (2017b). A proposed surface resistance model for the Penman-Monteith formula to estimate evapotranspiration in a solar greenhouse. J. Arid Land 4, 530-546. https://doi.org/10.1007/ s40333-017-0020-8.

Gong, X.W., Liu, H., Sun, J.S., Gao, Y., and Zhang, H. (2019). Comparison of Shuttleworth-Wallace model and dual crop coefficient method for estimating evapotranspiration of tomato cultivated in a solar greenhouse. Agric. Water Manag. 217, 141-153. https://doi. org/10.1016/j.agwat.2019.02.012.

Impron, I., Hemming, S., and Bot, G.P.A. (2008). Effects of cover properties, ventilation rate, and crop leaf area on tropical greenhouse climate. Biosyst. Engin. 99(4), 553-564. https://doi.org/10.1016/j. biosystemseng.2007.11.003.

Iritz, Z., Lindroth, A., Heikinheimo, M., Grelle, A., and Kellner, E. (1999). Test of a modified Shuttleworth-Wallace estimate of boreal forest evaporation. Agric. For. Meteorol. 98-99, 605-619. https:// doi.org/10.1016/S0168-1923(99)00127-6.

Juhász, A., and Hrotkó, K. (2014). Comparison of the transpiration part of two sources evapotranspiration model and the measurements of sap flow in the estimation of the transpiration of sweet cherry orchards. Agric. Water Manag. 143(9), 142-150. https://doi. org/10.1016/j.agwat.2014.06.014.

Kato, T., Kimura, R., and Kamichika, M. (2004). Estimation of evapotranspiration, transpiration ratio and water-use efficiency from a sparse canopy using a compartment model. Agric. Water Manag. 65(3), 173-191. https://doi.org/10.1016/j.agwat.2003.10.001.

Kool, D., Agam, N., Lazarovitch, N., Heitman, J.L., Sauer, T.J., and Ben-Gal, A. (2014). A review of approaches for evapotranspiration partitioning. Agric. For. Meteorol. 184, 56-70. https://doi. org/10.1016/j.agrformet.2013.09.003. 
Lei, S.L., Sun, Z.F., Lei, T.W., and Qi, W.Q. (2004). Vapor transfer resistance in leaf-air system of crops based on micro-climate in the greenhouse. J. Trans. CSAE 20(6), 46-50 (in Chinese with English abstract).

Li, S.E., Kang, S.Z., Zhang, L., Ortega-Farias, S., Li, F.S., Du, T.S., Tong, L., Wang, S.F., Ingman, M., and Guo, W.H. (2013). Measuring and modeling maize evapotranspiration under plastic film-mulching condition. J. Hydrol. 503(1), 153-168. https://doi.org/10.1016/j. jhydrol.2013.07.033.

Li, Y.K., Wang, L.C., Xue, X.Z., Guo, W.Z., Xu, F., Li, Y.L., Sun, W.T., and Chen, F. (2017). Comparison of drip fertigation and negative pressure fertigation on soil water dynamics and water use efficiency of greenhouse tomato grown in the North China Plain. Agric. Water Manag. 184,1-8. https://doi.org/10.1016/j.agwat.2016.12.018.

Liu, H., Sun, J.S., Duan, A.W., Sun, L., and Shen, X.J. (2008). Experiment on soil evaporation among plant of Chinese cabbage in sunlight greenhouse. J. Soil Water Conserv. 22(1), 207-211 (in Chinese with English abstract).

Liu, H., Sun, J.S., Duan, A.W., Sun, L., Liu, Z.G., and Shen, X.J. (2009a). Experiment on soil evaporation of radish in sunlight greenhouse. J. Trans. CSAE 25, 176-180 (in Chinese with English abstract).

Liu, H., Sun, J.S., Duan, A.W., Sun, L., and Liang, Y.Y. (2009b). Simple model for tomato and green pepper leaf area based on AutoCAD software. Chin. Agric. Sci. Bull. 25, 287-293.

Liu, S.Y., Wang, Y.K., Wei, X.D., Wei, X.G., Wang, X., and Zhang, L.L. (2013a). Measured and estimated evapotranspiration of Jujube (Ziziphus jujuba) forests in the Loess Plateau. China Int. J. Agric. Biol. 15(5), 811-819.

Liu, H., Duan, A.W., Li, F.S., Sun, J.S., Wang, Y.C., and Sun, C.T. (2013b). Drip irrigation scheduling for tomato grown in solar greenhouse based on pan evaporation in North China Plain. J. Integr. Agric. 12(3), 520-531. https://doi.org/10.1016/S2095-3119(13)60253-1.

Medrano, E., Lorenzo, P., Sánchez-Guerrero, M.C., and Montero, J.I. (2005). Evaluation and modelling of greenhouse cucumber-crop transpiration under high and low radiation conditions. Sci. Hortic. 105(2), 163-175. https://doi.org/10.1016/j.scienta.2005.01.024.

Ortega-Farias, S., Olioso, A., Antonioletti, R., and Brisson, N. (2004). Evaluation of the Penman-Monteith model for estimating soybean evapotranspiration. Irrig. Sci. 23(1), 1-9. https://doi.org/10.1007/ s00271-003-0087-1.

Ortega-Farias, S., Carrasco, M., Olioso, A., Acevedo, C., and Poblete, C. (2007). Latent heat flux over a Cabernet Sauvignon vineyard using the Shuttleworth and Wallace model. Irrig. Sci. 25(2), 161-170. https://doi.org/10.1007/s00271-006-0047-7.

Ortega-Farias, S., Poblete-Echeverría, C., and Brisson, N. (2010). Parameterization of a two-layer model for estimating vineyard evapotranspiration using meteorological measurements. Agric. For. Meteorol. 150, 276-286. https://doi.org/10.1016/j. agrformet.2009.11.012

Qiu, R.J., Kang, S.Z., Du, T.S., Tong, L., Hao, X.M., Chen, R.Q., Chen, J.L., and Li, F.S. (2013). Effect of convection on the Penman-Monteith model estimates of transpiration of hot pepper grown in solar greenhouse. Sci. Hortic. 160(3), 163-171. https://doi.org/10.1016/j. scienta.2013.05.043.

Qiu, R.J., Liu, C.W., Cui, N.B., Wu, Y.J., Wang, Z.C., and Li, R.G. (2019a). Evapotranspiration estimation using a modified Priestley-Taylor model in a rice-wheat rotation system. Agric. Water Manag. 224, 1-13. https://doi.org/10.1016/j.agwat.2019.105755.

Qiu, R.J., Liu, C.W., Li, F.S., Wang, Z.C., Yang, Z.Q., and Cui, N.B. (2019b). An investigation on possible effect of leaching fractions physiological responses of hot pepper plants to irrigation water salinity. BMC Plant Biol. 19, 297-307. https://doi.org/10.1186/s12870-019-1910-z.
Shuttleworth, W.J., and Wallace, J.S. (1985). Evaporation from sparse crops an energy combination theory. Q.J.R. Meteorol. Soc. 111(469), 839-855. https://doi.org/10.1002/qj.49711146910.

Willmott, C.J., and Matsuura, K. (2005). Advantages of the mean absolute error (MAE) over the root mean square error (RMSE) in assessing average model performance. Clim. Res. 30(1), 79-82. https://doi.org/10.3354/cr030079.

Yan, H.F., Shi, H.B., Oue, H., Zhang, C., Xue, Z., Cai, B., and Wang, G.Q. (2015). Modeling bulk canopy resistance from climatic variables for predicting hourly evapotranspiration of maize and buckwheat. Meteorol. Atmosf. Phys. 127(3), 305-312. https://doi.org/10.1007/ s00703-015-0369-1.

Yan, H.F., Zhang, C., Gerrits, M.C., Acquah, S.J., Zhang, H.N., Wu, H.M., Zhao, B.S., Huang, S., and Fu, H.W. (2018). Parametrization of aerodynamic and canopy resistances for modeling evapotranspiration of greenhouse cucumber. Agric. For. Meteorol 262, 370-378. https://doi.org/10.1016/j.agrformet.2018.07.020.

Yang, P.J., Hu, H.C., Tian, F.Q., Zhang, Z., and Dai, C. (2016). Crop coefficient for cotton under plastic mulch and drip irrigation based on eddy covariance observation in an arid area of northwestern China. Agric. Water Manag. 171, 21-30. https://doi.org/10.1016/j. agwat.2016.03.007.

Yang, Y.T., and Song, S.H. (2012). Comparison of dual-source evapotranspiration models in estimating potential evaporation and transpiration. Trans. CSAE 28(24), 176-180 (in Chinese with English abstract)

Yuan, B.Z., Kang, Y.H., and Nishiyama, S. (2001). Drip irrigation scheduling for tomatoes in unheated greenhouses. Irrig. Sci. 20(3), 149-154. https://doi.org/10.1007/s002710100039.

Zhang, B.Z., Kang, S.Z., Li, F.S., and Zhang, L. (2008). Comparison of three evapotranspiration models to Bowen ratio-energy balance method for a vineyard in an arid desert region of northwest China. Agric. For. Meteorol. 148(10), 1629-1640. https://doi. org/10.1016/j.agrformet.2008.05.016.

Zhao. P., Li, S.E., Li, F.S., Du, T.S., Tong, L., and Kang, S.Z. (2015) Comparison of dual crop coefficient method and ShuttleworthWallace model in evapotranspiration partitioning in a vineyard of northwest China. Agric. Water Manag. 160, 41-56. https://doi. org/10.1016/j.agwat.2015.06.026

Received: Aug. 20, 2019

Accepted: Nov. 21, 2019

Addresses of authors:

X.W. Gong ${ }^{1}$, J.K. Ge' ${ }^{1}$, Y.B. Li ${ }^{1}$, S.S. Wang ${ }^{1}$, H. Zhang ${ }^{1}$, L. Zhang ${ }^{1}$, Y.F. Liu ${ }^{1}$ and $\mathrm{H}$. Liu ${ }^{2}$,

${ }^{1}$ School of Water Conservancy, North China University of Water Resources and Electric Power; Henan Key Laboratory of Water-saving Agriculture, Zhengzhou, 450046, China

${ }^{2}$ Ministry of Agriculture and Rural Affairs / Farmland Irrigation Research Institute, Chinese Academy of Agricultural Sciences, Xinxiang, 453002, China

* Corresponding author; E-mail: liuhao-914@163.com 
International Workshop on Vertical Farming

13-15 October 2019

Wageningen, The Netherlands

Sponsored by
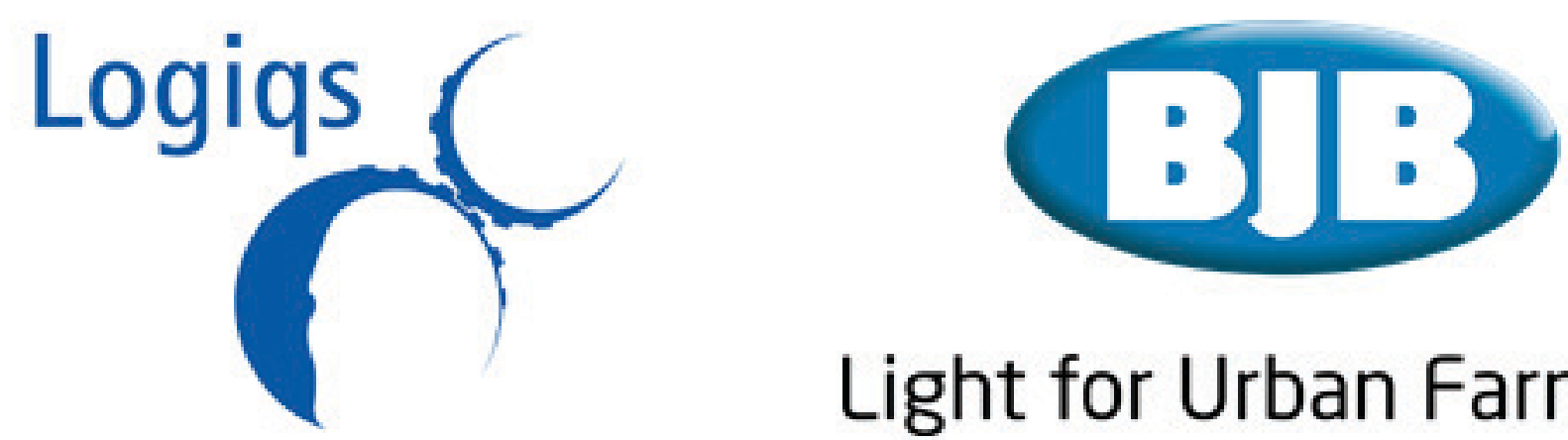

\section{Light for Urban Farming}

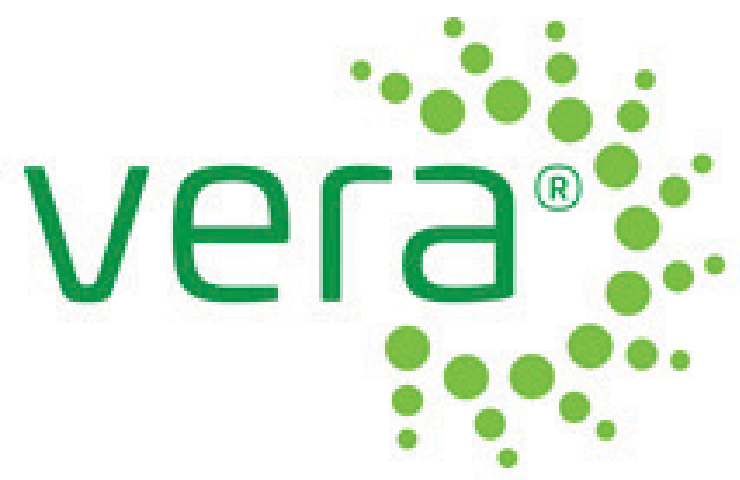

Nouryon

\section{Chelated} Micronutrients
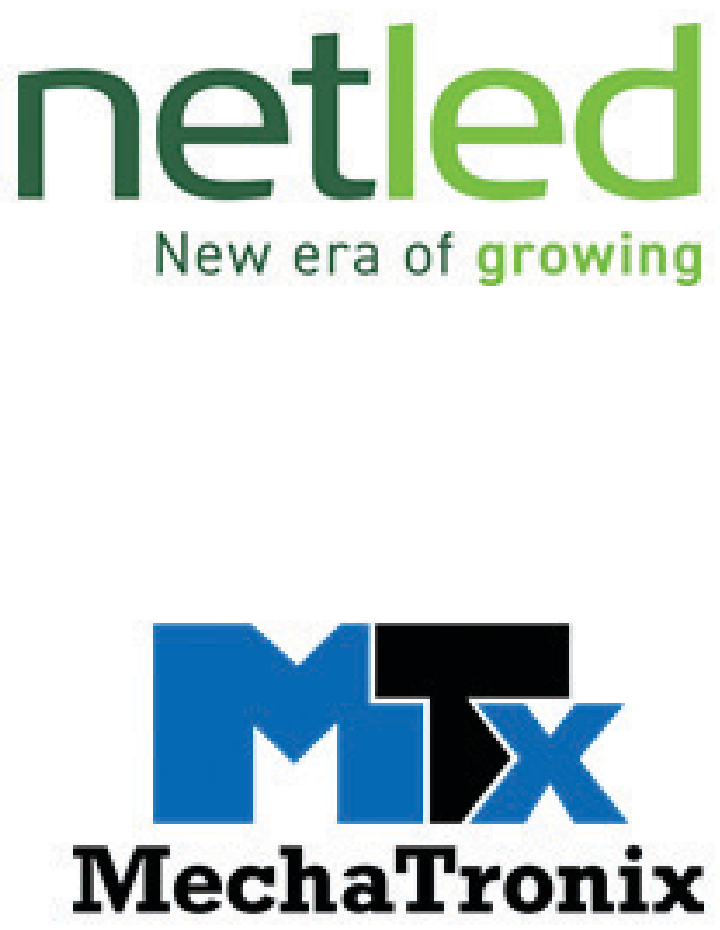

Fடㅁㅁய

$$
\text { F L U E N C E }
$$

